\title{
CARBON-BASED SORBENTS IMPREGNATED WITH IRON OXIDES FOR REMOVING MERCURY IN ENERGY GENERATION PROCESSES
}

\author{
J. R. Trobajo, C. Antuña-Nieto, E. Rodríguez*, R. García, M. A. López-Antón,
} M. R. Martínez-Tarazona.

Instituto Nacional del Carbón, CSIC, Francisco Pintado Fe 26, 33011 Oviedo, Spain

${ }^{*}$ Corresponding author:

Phone: +34 985119090

Fax: +34 985297662

Email: elena@incar.csic.es 


\section{ABSTRACT}

Gaseous phase mercury emissions into the atmosphere from fossil fuel combustion processes for energy production are a matter of serious environmental concern. Several technologies have been studied and proposed to address this problem, but none of them is mature enough from a commercial point of view. This study aims to provide new insights into the interaction between mercury and iron oxides in order to enable the design of cost-effective mercury capture technology based on regenerable sorbents. Different iron oxides supported on an activated carbon were prepared and tested for the removal of elemental mercury $\left(\mathrm{Hg}^{0}\right)$ under different experimental conditions. It was found that 1) maghemite promoted the removal of mercury to a greater extent than goetite/hematite achieving $100 \%$ efficiencies and 2) the mercurysorbent interaction is determined by the oxygen vacancies present in the iron oxide. The mercury retention efficiency is maintained after the sorbent is regenerated and it is not deactivated by the presence of acid gases. The results obtained with the sorbent loaded with maghemite open new perspectives for the retention of gaseous $\mathrm{Hg}^{0}$, combining high efficiency, good regenerability and lower price in comparison with sorbents developed to date. Once the regeneration capacity is assessed, the adsorption process will be scaled.

Keywords: Mercury, iron oxides, sorbents, regenerable. 


\section{Nomenclature}

$\mathrm{AC}$

activated carbon Norit RB3

ACFex

activated carbon with hematite/goethite. $\mathrm{x}$ is the percentage

of Fe; i.e. ACFe10 means $10 \% \mathrm{Fe})$

ACFex-800 activated carbon with magnetite/maghemite. $\mathrm{x}$ is the

percentage of $\mathrm{Fe}$, i.e. ACFe10-800 means $10 \% \mathrm{Fe}$

BET

Brunauer-Emmett- Teller equation.

DFT

Density Functional Theory

EDAX

energy-dispersive X-ray spectroscope

ESPs electrostatic precipitators

$\mathrm{Hg}^{0}$

elemental gaseous mercury

$\mathrm{Hg}^{2+}$

oxidized gaseous mercury

$\mathrm{Hg}_{\mathrm{p}}$

particulate-bound mercury

MCD

Multiplier Channeltron Detector

$\mathrm{MeHg}$

methylmercury

$\mathrm{NO}$

Nitrogen oxides ( $\mathrm{NO}$, and $\mathrm{NO}_{2}$ )

SEM

Scanning Electron Microscopy

$\mathrm{S}_{\mathrm{BET}}$

Specific surface area $\left(\mathrm{m}^{2} \mathrm{~g}^{-1}\right)$

WFGD

Wet Flue Gas Desulfurization

XRD

X-ray diffraction

XPS

X-ray photoelectron spectroscopy 


\section{Introduction}

Mercury is a metal well-known for its toxicity to humankind and ecosystems. In Europe, the greatest anthropogenic contribution of mercury to the environment is its release from coal-fired power plants. It is estimated that 7.5 Ton per year of mercury are emitted from this source of electric power generation [1]. Mercury can be emitted during coal combustion processes in three forms, namely, elemental gaseous mercury $\left(\mathrm{Hg}^{0}\right)$, oxidized gaseous mercury $\left(\mathrm{Hg}^{2+}\right)$, and particulate-bound mercury $\left(\mathrm{Hg}_{\mathrm{p}}\right)$. The speciation of the mercury emitted dictates its subsequent lifetime and fate in the atmosphere. For instance, $\mathrm{Hg}^{2+}$ is soluble in water and can easily enter water sources, where it is converted into methylmercury $(\mathrm{MeHg})$ by anaerobic bacteria. Of all the mercury species $\mathrm{MeHg}$ is the most dangerous. High concentrations of this species are detected in some fish, which are one of the main sources of human exposure. On the other hand, elemental mercury can be transported long distances in the atmosphere, where its toxic effects have an impact on a global scale [2]. All these facts suggest that the speciation of mercury throughout the combustion process may be determinant for the design of an effective mercury removal technology.

Gaseous oxidized mercury $\left(\mathrm{Hg}^{2+}\right)$ and particulate-bound mercury $\left(\mathrm{Hg}_{\mathrm{p}}\right)$ can be removed efficiently in the wet flue gas desulfurization (WFGD) units and in the electrostatic precipitators (ESPs) respectively, already installed in most power plants. However, elemental mercury vapor $\left(\mathrm{Hg}^{0}\right)$ is not retained in typical air-pollution control devices, due to its insolubility in water, high vapor pressure, and semi-noble metal properties $[3,4]$. 
Nowadays, there are several possibilities to address the problem of the capture of $\mathrm{Hg}^{0}$ on sorbents, with a state-of-the-art overview having been already published [5]. Of all the different possibilities, the injection of activated carbons is the main technology considered for the retention of mercury. In particular, activated carbons impregnated with sulphur or halogens have proved to be very successful [6]. However, this technology entails serious difficulties such as high cost, a high carbon to mercury ratio, a large amount of toxic waste and adverse impacts on the commercial value of fly ash [7].

A gas cleaning process based on regenerable sorbents seems to be an attractive alternative to the injection of conventional solid sorbents $[7,8]$. These regenerable sorbents could be located in a power plant at the end of the cycle and would avoid the generation of waste contaminated with mercury. Therefore, they could be used in conventional coal combustion plants and also in other processes such as oxy-coal combustion, $\mathrm{CO}_{2}$ purification or natural gas production [8-12].

Sorbents loaded with noble metals such as gold and silver have been tested for mercury capture taking advantage of their great capacity to retain mercury through amalgamation and their possibility of regeneration over several cycles $[4,13,14]$. However, the search for another type of sorbents containing reactive metals such as carbons loaded with metal oxides would represent a low-cost alternative that should also be considered. Regenerable sorbents based on manganese oxides have shown a good capacity to capture mercury under oxidizing conditions (combustion flue gas), but in the absence of oxygen in the gas (gasification conditions, $\mathrm{CO}_{2}$ purification etc.) these sorbents were less effective [15]. 
Several studies claim that the iron oxides present in the fly ashes produced by the combustion of coal have a significant catalytic activity for the adsorption and oxidation of $\mathrm{Hg}^{0}$, favoring the formation of $\mathrm{Hg}_{\mathrm{p}}$ in the process $[16,17]$. However, the exact mechanism under which gaseous mercury species interact with iron oxides is difficult to determine. There are several conditions that can affect the process, such as temperature, gas composition, iron oxide structure, and composition of fly ash (unburned carbon and other transition metal oxides). Some bench-scale research indicated that iron oxides promote the oxidation of mercury in the presence of $\mathrm{NO}_{\mathrm{x}}$ and $\mathrm{HCl}[16,18]$, and more recently a model has been proposed to predict the oxidation of mercury by $\mathrm{HCl}$ over $\mathrm{Fe}_{2} \mathrm{O}_{3}$ [17]. Besides, studies carried out on maghemite $\left(\mathrm{\gamma}-\mathrm{Fe}_{2} \mathrm{O}_{3}\right)$, a polymorph of hematite $\left(\alpha-\mathrm{Fe}_{2} \mathrm{O}_{3}\right)$ that also occurs in fly ash, suggested that maghemite promotes the adsorption of $\mathrm{Hg}^{0}$ from simulated coal combustion flue gases through noncatalytic processes $[18,19]$. Recently, magnetic biochars loaded with magnetite $\left(\mathrm{Fe}_{3} \mathrm{O}_{4}\right)$ have been investigated for the capture of $\mathrm{Hg}^{0}$, showing $\mathrm{Hg}^{0}$ adsorption capacity and adsorption rate higher than that obtained for a commercial brominated activated carbon, specially designed for this purpose, under simulated flue gas at $120{ }^{\circ} \mathrm{C}$ [20]. The authors suggested that $\mathrm{Fe}^{3+}$ in tetrahedral coordination acts as an active adsorption/oxidation site for $\mathrm{Hg}^{0}$, which results in the formation of iron amalgamation. In addition, the iron oxides gave rise to the formation of oxygen-rich functional groups on the surface of the sorbent, which also participate in the adsorption of $\mathrm{Hg}^{0}$ [20]. The possibility of regenerating the sorbent was not evaluated in the mentioned study.

The sorbents developed in this work open new perspectives for the retention of gaseous $\mathrm{Hg}^{0}$. As already described, up to now, the capture of 
gaseous $\mathrm{Hg}^{0}$ had been carried out either with solid sorbents impregnated with reagents such as $\mathrm{S}$ or $\mathrm{Cl}$, which were for a single use, and eventually constituted a waste, or with regenerable sorbents impregnated with noble metals, which have very good performance and outstanding behavior and efficiency, but require a high economic investment. The sorbents developed in this work combines high efficiency, good regenerability and affordable price, with characteristics that could be closer to those of materials doped with noble metals, which opens up enormous outlooks in the field of regenerable sorbents.

\section{Experimental}

\subsection{Materials synthesis}

The commercial activated carbon Norit RB3 (Cabot Norit Nederland B.V.), was used as the iron oxides support (AC). The extruded activated carbon as commercialized was grounded between 0.2 and $0.5 \mathrm{~mm}$ before being treated. The impregnation with iron consisted of wetting the support with a dissolution of $\mathrm{Fe}\left(\mathrm{NO}_{3}\right)_{3} \cdot 9 \mathrm{H}_{2} \mathrm{O}$ (> 98\%, Fisher) followed by a thermal treatment [21]. In a typical impregnation procedure, $1.0 \mathrm{~g}$ of $\mathrm{AC}$ was pre-dried in an oven at $80{ }^{\circ} \mathrm{C}$ overnight. Then, the $\mathrm{AC}$ was impregnated with a $0.6 \mathrm{M}$ solution of $\mathrm{Fe}\left(\mathrm{NO}_{3}\right)_{3} \cdot 9$ $\mathrm{H}_{2} \mathrm{O}$ in ethanol (99\%, Scharlau). The solution was added dropwise to incipient wetness and then the sample was dried at $60{ }^{\circ} \mathrm{C}$ under vacuum. This process was repeated several times until the amount of iron nitrate infiltrated was equivalent to the selected concentration $(5,10,20,35$ or 50 wt.\% of $\mathrm{Fe}$ in the AC). Finally, the sample was heated in an oven at $200{ }^{\circ} \mathrm{C}$ overnight. This treatment results in the formation of iron oxides hematite $\left(\alpha-\mathrm{Fe}_{2} \mathrm{O}_{3}\right)$ and goethite 
$(\mathrm{FeO}(\mathrm{OH}))$ on the surface of the support. The samples prepared were designated ACFex, where $\mathrm{x}$ is the percentage of Fe. An additional heat treatment at $800{ }^{\circ} \mathrm{C}$ was carried out for an hour in an inert atmosphere to transform the above iron oxides into magnetic ones. In this case, the sample was designated with the temperature after its code (ACFex-800).

\subsection{Materials characterization}

The amount of iron and its distribution on the surface of the activated carbon were studied by Scanning Electron Microscopy (SEM) using a Quanta FEG 650 instrument (FEI Company, US). This instrument was connected to a dispersive X-ray analyzer (EDAX) equipped with an Apollo X detector (Ametek, US).

The crystalline structure of the prepared samples was examined by X-ray diffraction (XRD) in a Bruker D8 power diffractometer (US), equipped with a göbel mirror in the incident beam and a parallel-slits analyzer in the diffracted beam. A general scan between $20^{\circ}$ and $80^{\circ}(2 \theta)$ was performed with a step size of $0.02^{\circ} \mathrm{s}^{-1}$ and a step time of $2 \mathrm{~s}$. Additionally, a specific scan between 50 and

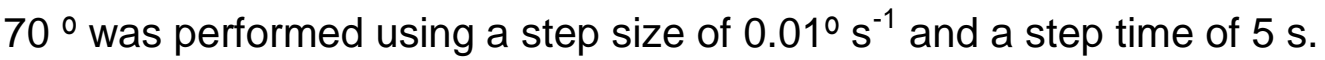

X-ray photoelectron spectroscopy (XPS) analyses were carried out to identify the surface chemical composition and valence state of FeOx/AC. The analyses were performed using a Specs spectrometer (Germany) equipped with a high performance Phoibos 100 hemispherical analyzer and a 5 multiplier channeltron detector (5MCD). The X-ray radiation was a non-monochromatic $\mathrm{Mg} \mathrm{Ka}(1253.6 \mathrm{eV})$ emitted from a double anode at $50 \mathrm{w}$. 
The specific surface area $\left(\mathrm{S}_{\mathrm{BET}}\right)$ of the samples was determined from the analysis of the $\mathrm{N}_{2}$ adsorption isotherms in a relative pressure range of 0.01 to 0.20, using the Brunauer-Emmett-Teller (BET) equation. The nitrogen adsorption isotherms at $-196{ }^{\circ} \mathrm{C}$ were obtained using a Micromeritics ASAP 2420 analyzer. Prior to adsorption measurements, all samples were outgassed at $180{ }^{\circ} \mathrm{C}$ for $12 \mathrm{~h}$ under vacuum.

\subsection{Experimental device for mercury retention}

The experimental device used for the retention of $\mathrm{Hg}$ at a laboratory scale is similar to that described elsewhere [22]. It consists of a glass reactor heated by a furnace, where $\sim 200 \mathrm{mg}$ of sorbent are placed. The gas phase $\mathrm{Hg}^{0}$ $\left(100 \mu \mathrm{g} \mathrm{m}^{-3}\right)$ was obtained from a calibrated permeation tube (VICI Metronic, US) and was brought to the reactor by a $\mathrm{N}_{2}$ stream of $200 \mathrm{ml} \mathrm{min}^{-1}$. Atmospheres consisting of blends of two or more gases $-\mathrm{O}_{2}, \mathrm{CO}_{2}$ and $\mathrm{N}_{2}$ in major concentrations and $\mathrm{SO}_{2}$ and $\mathrm{HCl}$ in trace concentrations- were incorporated into the $\mathrm{Hg}^{0}$ gas stream to assess the influence of each gas on the retention of mercury. The temperature of the reactor was kept at $140{ }^{\circ} \mathrm{C}$ or 40 ${ }^{\circ} \mathrm{C}$. All gas lines where heated to prevent mercury condensation. A continuous $\mathrm{Hg}$ gas analyzer (VM 3000; Mercury Instruments, Germany) was used to monitor the $\mathrm{Hg}^{0}$. At the outlet of the reactor, a bed of Dowex® $1 \times 8$ ion exchange resin was placed to determine the oxidized mercury $\left(\mathrm{Hg}^{2+}\right)$, which could be originated by homogeneous or heterogeneous oxidation during the experiments [23]. The total amount of $\mathrm{Hg}$ retained in the sorbents and the $\mathrm{Hg}^{2+}$ captured in the resin were analyzed using a LECO Mercury Analyzer (US), AMA 254. Each sample was analyzed at least 2 times. The confidence limit of the results is 
given as the standard deviation represented as error bars in the Figures. The adsorption of mercury was followed for approximately 1200 min (20 h).

\subsection{Sorbent regeneration}

Regeneration was carried out by heating the post-retention sorbents from 40 to $450 \stackrel{\circ}{\circ} \mathrm{C}$, at a heating rate of $3{ }^{\circ} \mathrm{C} \mathrm{min}^{-1}$, under a $\mathrm{N}_{2}$ flow of $500 \mathrm{~mL} \mathrm{~min}{ }^{-1}$. The desorbed $\mathrm{Hg}^{0}$ was monitored as a function of temperature using the VM3000 analyzer. The regenerated sorbents were then reused to capture mercury.

\section{Results}

\subsection{Sample characterization}

The SEM images shown in Fig. 1 demonstrate that the iron oxides particles were deposited on the AC surface after impregnation. The ACFe10 sample displays a smooth layer of iron oxides with some cracks throughout the carbon matrix (Figs. $1 \mathrm{a}$ and 1 b). The subsequent carbonization at $800{ }^{\circ} \mathrm{C}$ of the sample significantly affected its morphology, obtaining a homogeneous dispersion of iron oxides particles in the ACFe10-800 sample (Fig. 1C). A higher magnification of the surface (Fig. 1d) shows the presence of cubic shaped particles. The surface iron content estimated by EDAX analysis ranges from 20 to $35 \%$ for both samples, ACFe10 and ACFe10-800. 

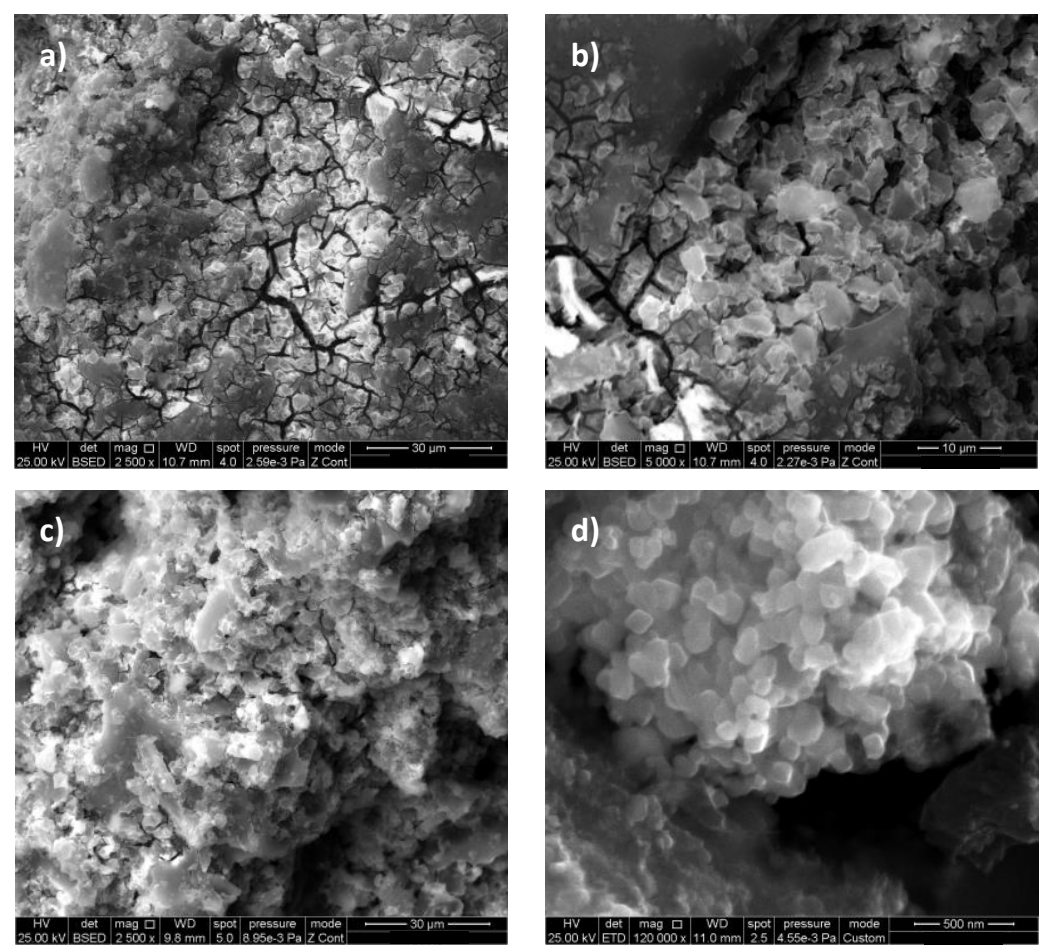

Fig. 1. SEM images corresponding to ACFe10 (a, b) and ACFe10-800 (d,e).

The crystalline structures were studied by X-ray diffraction (XRD). As shown in Fig. 2, the ACFe10 sample exhibited two broad bands at 26 and $43^{\circ}$, which are associated with the turbostratic structure typical of activated carbon (amorphous carbon). An additional broad peak at $35^{\circ}$ was observed corresponding to iron oxide phases, which suggests that iron oxides are present in a short range of structural order. Even though its position is in the range of the (311) peak for iron oxides with spinel structure (magnetite/maghemite), it is not possible to accurately identify the nature of iron oxides, since hematite/goethite (iron oxides with corundum structure) also present XRD peaks in this $2 \theta$ range. To deepen the characterization of these iron oxide species, the ACFe10 sample was analyzed by XPS. 


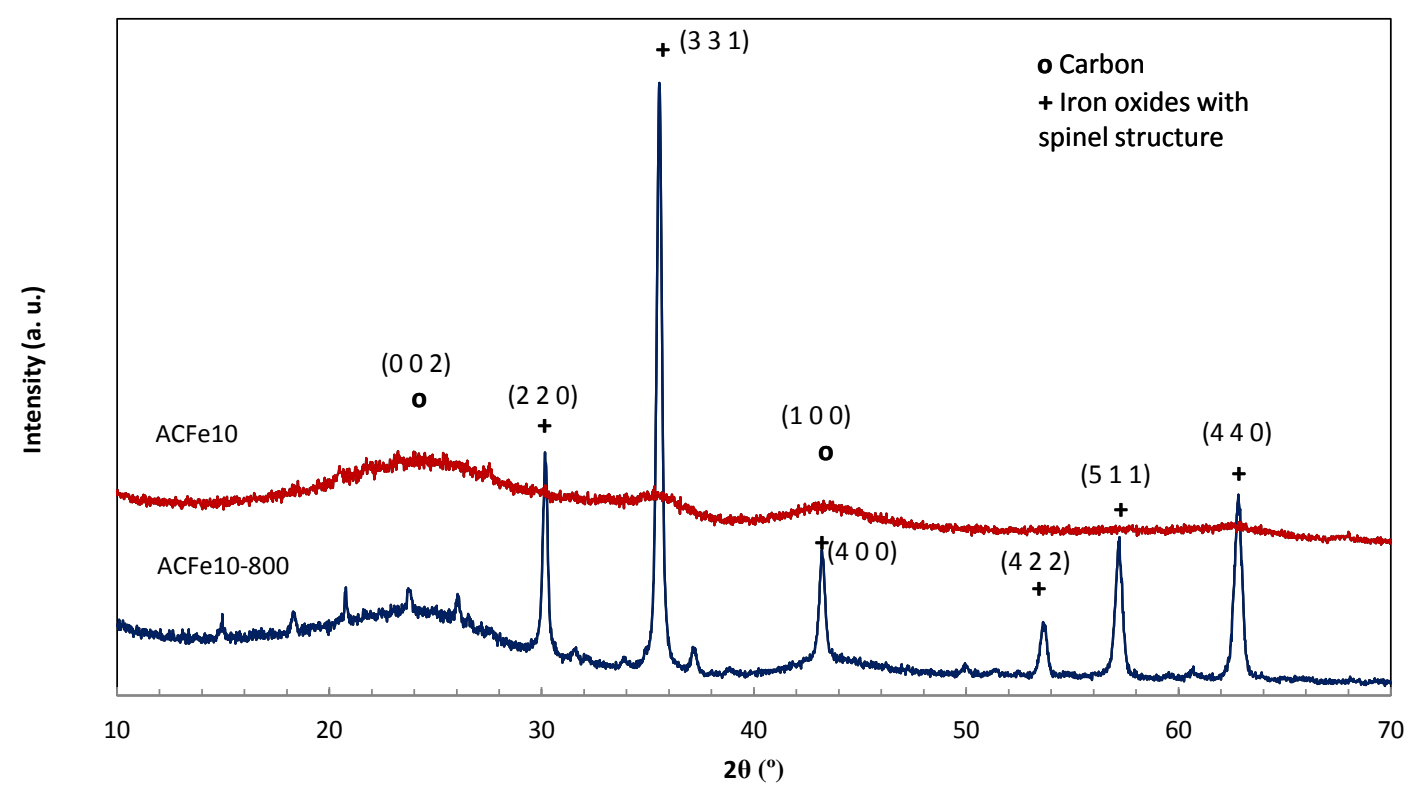

Fig. 2. X-ray diffraction patterns of samples ACFe10 and ACFe10-800. (+) Peaks indexed in the spinel structure (spatial group Fd $3 \bar{m}$ ).

The Fe $2 p$ region (Fig. 3) showed two peaks at 710.5 and $711.5 \mathrm{eV}(\mathrm{Fe}$ $2 p_{3 / 2}$ ), which can be assigned to oxidized $\mathrm{Fe}$ species, more likely to $\mathrm{Fe}^{3+}$ in iron oxides $\left(\mathrm{Fe}_{2} \mathrm{O}_{3}\right)$ and bonded to hydroxyl groups $(\mathrm{FeO}(\mathrm{OH})$, respectively [21, 24]. The peak at $724.5 \mathrm{eV}$ corresponds to the core level $\mathrm{Fe} 2 \mathrm{p}_{1 / 2}$ for $\mathrm{Fe}^{3+}$ compounds and the satellite component at $718.7 \mathrm{eV}$ is associated to iron oxidized species. Based on these results and others previously reported using the same method of impregnation with $\mathrm{Fe}\left(\mathrm{NO}_{3}\right)_{3} \cdot 9 \mathrm{H}_{2} \mathrm{O}$ [21], it can be suggested that before the heating treatment at $800{ }^{\circ} \mathrm{C}$ the iron species in the samples are composed mainly of hematite/goethite. 


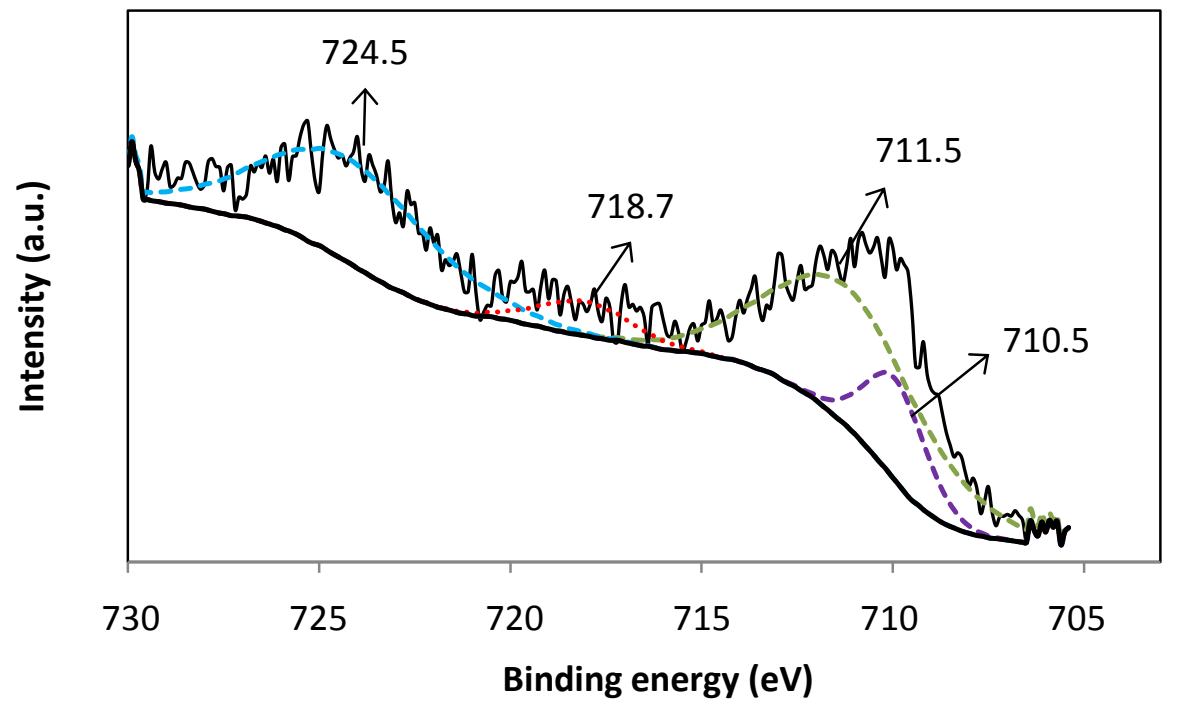

Fig. 3. XPS spectra of Fe $2 p$ for the sorbent ACFe10. Fe $2 p_{3 / 2}$ peaks at 711.5 and $710.5 \mathrm{eV}, \mathrm{Fe} 2 \mathrm{p}_{1 / 2}$ at $724.5 \mathrm{eV}$ and satellite component at $718.7 \mathrm{eV}$.

The X-ray diffraction pattern obtained after treatment at $800{ }^{\circ} \mathrm{C}$ (ACFe10-800) reveals the formation of iron oxide particles with a spinel crystalline structure: magnetite $\left(\mathrm{Fe}_{3} \mathrm{O}_{4}\right)$ and/or maghemite $\left(\mathrm{y}-\mathrm{Fe}_{2} \mathrm{O}_{3}\right)$ (Fig. 2), in which $1 / 3$ of the interstices are tetrahedrally coordinated with oxygen and 2/3 are coordinated octahedrally. In magnetite the tetrahedral sites are completely occupied by $\mathrm{Fe}^{3+}$ cations and the octahedral ones by equal amounts of $\mathrm{Fe}^{3+}$ and $\mathrm{Fe}^{2+}$. Maghemite is considered a fully oxidized magnetite, in which $\mathrm{Fe}^{3+}$ cations occupy only 5/6 of the total sites with the rest corresponding to vacancies [25]. The Iron oxides: Structure, properties, reactions, occurrence and uses (2nd. ed.). Weinheim: Wiley- $\mathrm{VCH}$. Each cell of maghemite contains 32 oxygen anions, $8 \mathrm{Fe}^{+3}$ cations occupy tetrahedral sites and additional $13^{1 / 3}$ are randomly located over the octahedral sites [19]. The vacancies, which compensate the oxidation of $\mathrm{Fe}^{2+}$, are confined to the octahedral sites. Due to its similar crystal structure magnetite and maghemite have similar XRD patterns, although their lattice 
parameters are slightly different. The lattice constant of $y-\mathrm{Fe}_{2} \mathrm{O}_{3}(0.8346 \mathrm{~nm})$ is slightly smaller than that of $\mathrm{Fe}_{3} \mathrm{O}_{4}(0.8396 \mathrm{~nm})$, so this parameter can be used to discern the nature of the iron oxide present in the sample [26]. From the shift in the peak (511) it is also possible to identify both species and even for a multiphase material to quantify its composition [27]. The lattice parameter calculated for the ACFe10-800 sample was $0.834 \mathrm{~nm}$, which indicates that the iron oxide phase is maghemite. In Fig. 4, it can also be seen that the sample presents a slight shift in the diffraction planes (511) and (440) in comparison with the commercial magnetite. The size of the crystallites was deduced by applying the Scherrer equation to the peak (311) of the XRD patterns and it was $35 \mathrm{~nm}$. It was calculated from the width at half height of the diffraction peak (311).

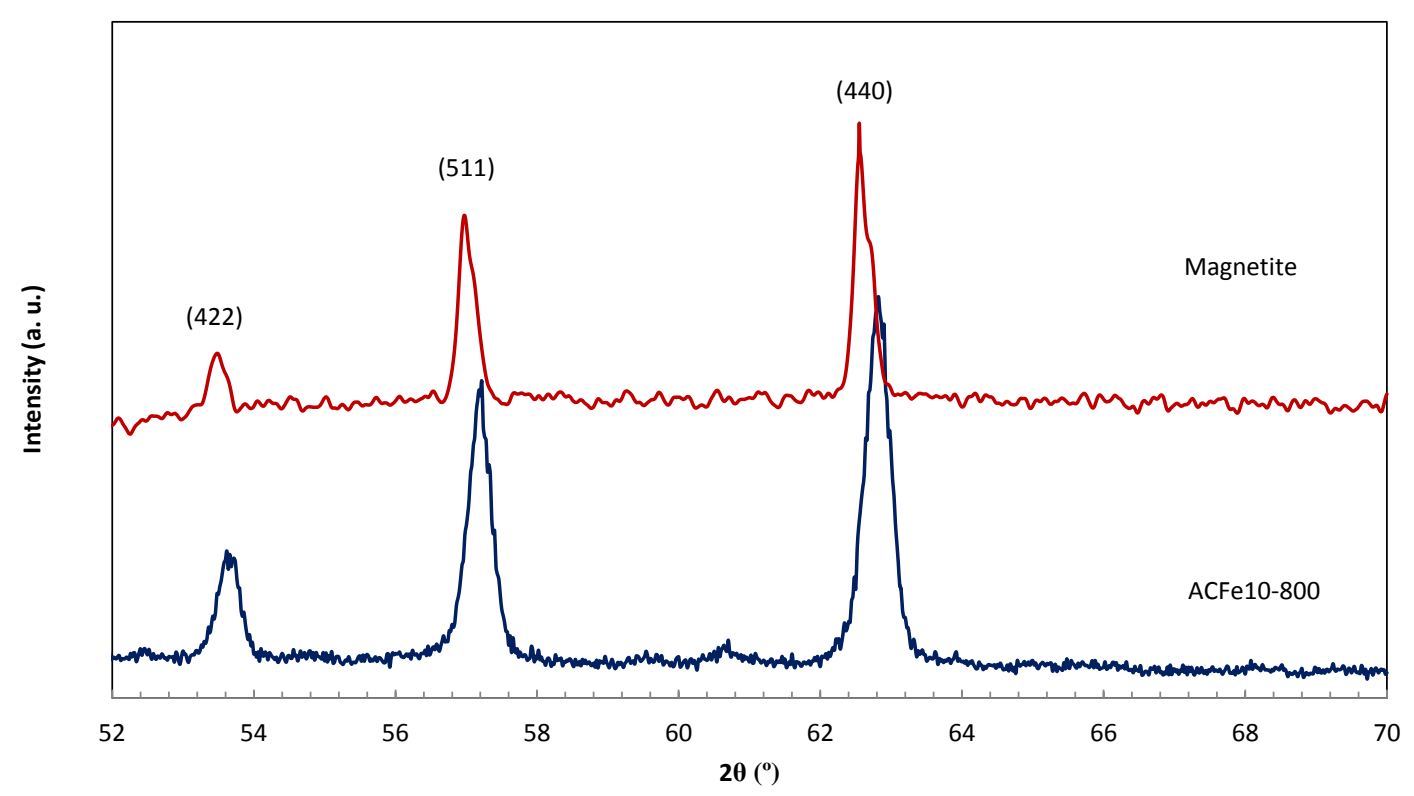

Fig. 4. Specific X-ray diffraction patterns collected at diffraction angles between

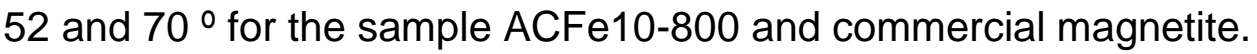


From these data it can be inferred that the impregnated sorbent has an amorphous layer of iron oxides composed of the hematite/goethite species. Further heat treatment at $800 \stackrel{\circ}{\circ}$ leads to maghemite, with a wide range of crystallinity. Therefore, under controlled conditions, non-magnetic iron oxides, such as hematite and goethite, can be converted into magnetic maghemite.

\subsection{Mercury removal performance}

\subsubsection{Effect of iron concentration}

Results demonstrated that iron species on AC play a role in the capture of $\mathrm{Hg}^{0}$ (Fig. 5). The influence of the iron concentration on the $\mathrm{Hg}^{0}$ removal performance was evaluated under an atmosphere of $\mathrm{N}_{2}+\mathrm{O}_{2}\left(13 \% \mathrm{v} / \mathrm{v} \mathrm{O}_{2}\right)$ at 140 ${ }^{\circ} \mathrm{C}$ in hematite/goethite sorbents (ACFex). In Fig. 5, it can be observed that the $\mathrm{Hg}^{0}$ removal capacity increases non-linearly with iron concentration, reaching the maximum adsorption for the sample impregnated with $20 \mathrm{wt} . \%$ : above this value the adsorption of mercury tends slightly to decrease.

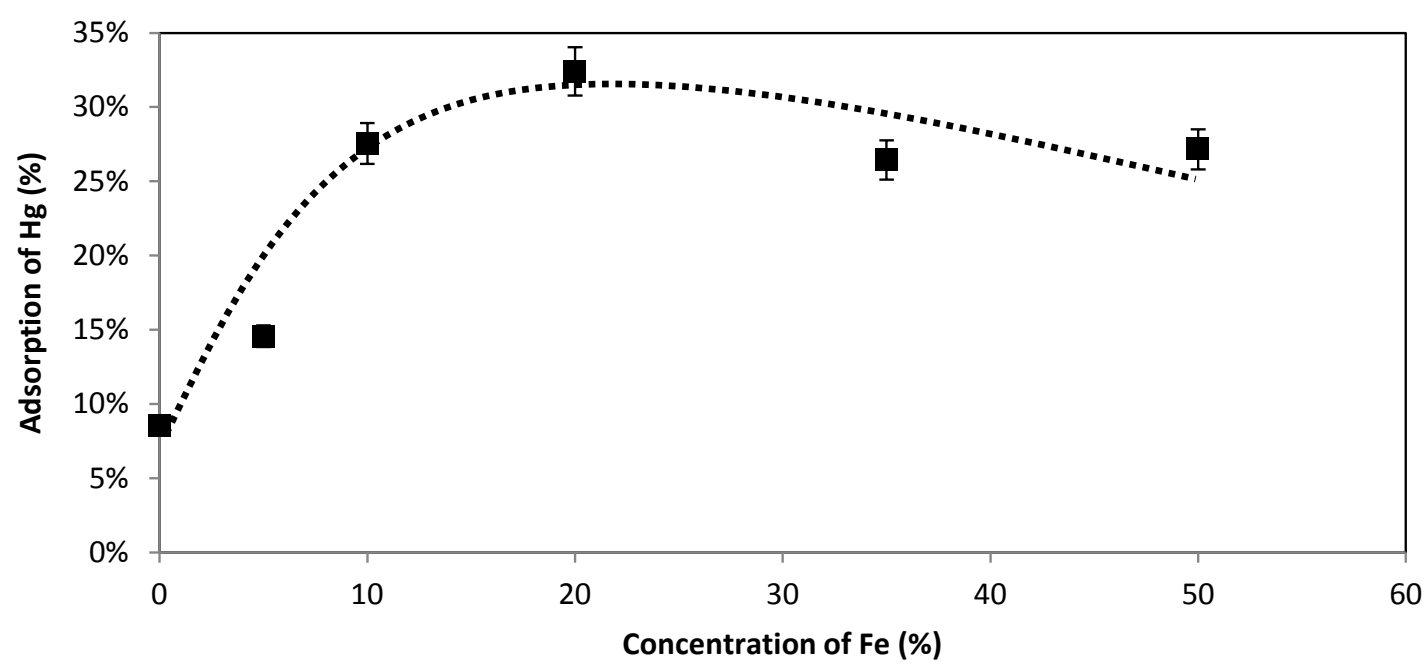


Fig.5. Mercury removal in sorbents with different iron content (ACFex), $x=$ percentage of $\mathrm{Fe}$.

The results indicate that the iron oxides create a series of active sites that favour the interaction between $\mathrm{Hg}^{0}$ and the sorbent. The decrease in $\mathrm{Hg}^{0}$ adsorption with iron concentrations of 35 and $50 \%$ can be attributed to a reduction in the textural parameters of the activated carbon. The sample impregnated with an iron concentration of $10 \mathrm{wt} . \%$ (ACFe10) displayed a BET surface $\left(\mathrm{S}_{\mathrm{BET}}\right)\left(1072 \mathrm{~m}^{2} \mathrm{~g}^{-1}\right)$ of the same order as the original $A C\left(1183 \mathrm{~m}^{2} \mathrm{~g}^{-1}\right)$, decreasing to 834 and $670 \mathrm{~m}^{2} \mathrm{~g}^{-1}$, in ACFe35 and ACFe50, respectively.

The effect of surface area was demonstrated by the evaluation of sorbents prepared with the same Fe concentrations but using activated carbon supports with a lower BET area (from 50 to $400 \mathrm{~m}^{2} \mathrm{~g}^{-1}$ ). In these cases, the adsorption capacities were lower than those obtained with AC of $1183 \mathrm{~m}^{2} \mathrm{~g}^{-1}$. As could be expected, a high surface area of the support favours the adsorption of mercury but, as will be discussed in the following sections, it is not the only factor to be taken into account.

\subsubsection{Effect of iron oxide}

The effect of the iron oxide type on mercury capture was evaluated with the sample impregnated with 10\% Fe (ACFe10), which represents a compromise between high mercury retention and low iron content (Fig. 5). As mentioned in previous sections (2.1. and 3.1.), the sorbents impregnated with iron were subjected to a heat treatment to transform goethite/hematite (weakly ferromagnetic or antiferromagnetic) into maghemite (ferromagnetic). As can be 
observed in Fig. 6, the heat-treated ACFe10-800 sorbent shows a mercury removal efficiency of almost $100 \%$, compared to the $35 \%$ efficiency achieved with the sorbent before the thermal treatment (ACFe10). The results imply that maghemite is much more efficient at removing mercury than goethite/hematite.

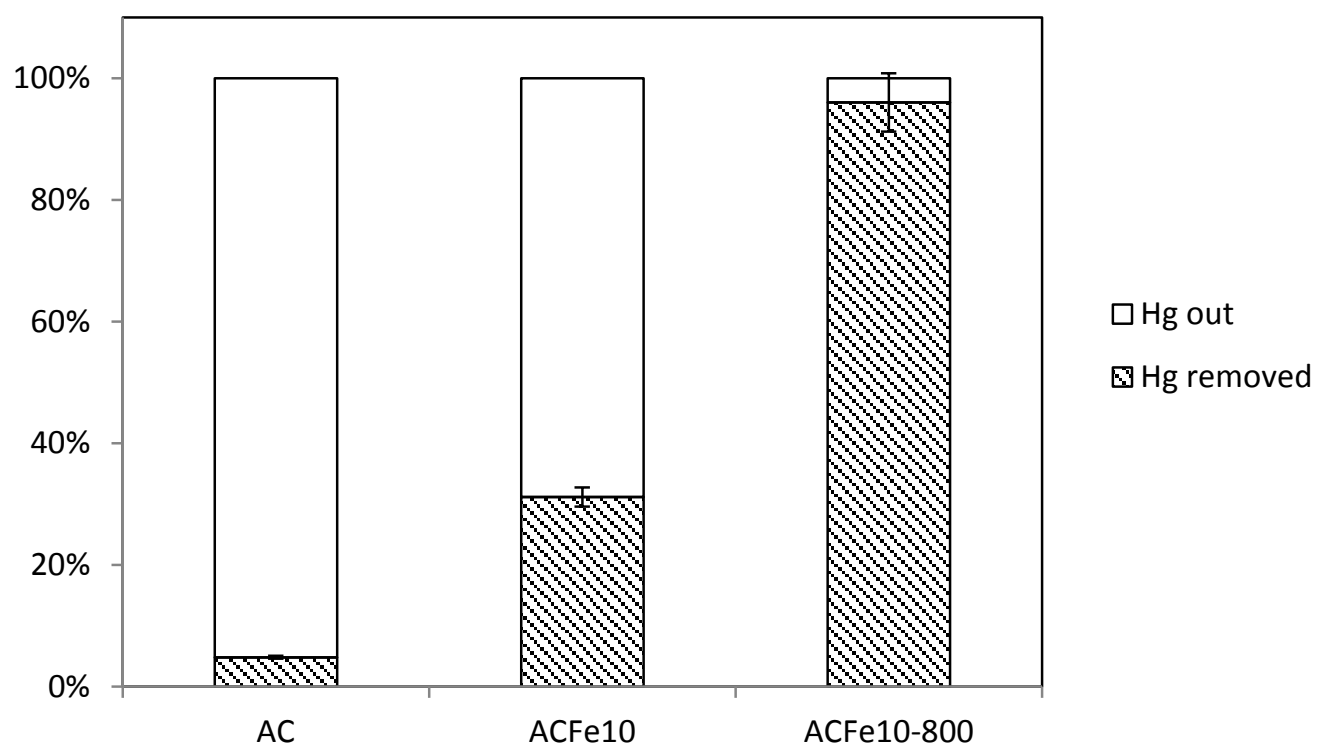

Fig. 6. Mercury removal with the activated carbon without iron (AC) and the sorbents having different iron oxides: goethite/hematite (ACFe10) and maghemite (ACFe10-800). Experimental conditions: atmosphere of $\mathrm{N}_{2}+\mathrm{O}_{2}$ $\left(13 \% \mathrm{v} / \mathrm{v} \mathrm{O}_{2}\right)$ at $140 \stackrel{\circ}{ } \mathrm{C}$.

\subsubsection{Performance of maghemite sorbent (ACFe10-800)}

\subsubsection{Effect of temperature.}

To determine the applicability of the developed sorbents, the retention capacity of $\mathrm{Hg}^{0}$ at low and high temperatures (40 and $\left.140^{\circ} \mathrm{C}\right)$ was evaluated. These temperatures can be considered as the lowest and the highest at which $\mathrm{Hg}^{0}$ can be present in the typical gases to be depurated in the production of 
energy. As already mentioned, the most common mode for the control of $\mathrm{Hg}^{0}$ consists of the injection of activated carbon in the flue gas upstream of the particle control systems, where the temperature ranges between 140 and 150 ${ }^{\circ} \mathrm{C}$. However, the main objective of the work is to explore the possibility of using these sorbents as regenerable sorbents at the end of the cycle where the temperature is lower. $100 \%$ mercury retention efficiencies were achieved with ACFe10-800 at both temperatures during two adsorption-desorption cycles (Fig. 7). No oxidized mercury $\left(\mathrm{Hg}^{2+}\right)$ was detected in the Dowex resin at any of the temperatures studied, suggesting the same type of mercury/ACFe10-800 interaction at 40 and $140^{\circ} \mathrm{C}$.
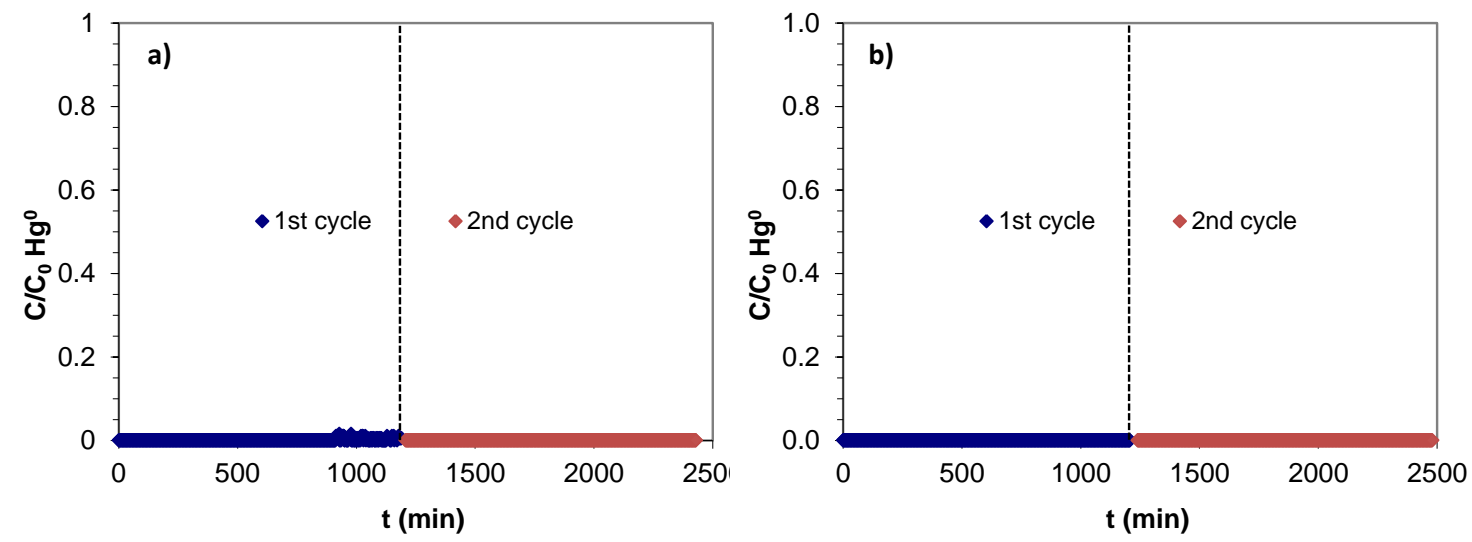

Fig. 7. Mercury adsorption for ACFe10-800 in an atmosphere of $\mathrm{N}_{2}+\mathrm{O}_{2}(13 \% \mathrm{v} / \mathrm{v}$ $\mathrm{O}_{2}$ ) during two adsorption-desorption cycles at: a) $140^{\circ} \mathrm{C}$ and b) $40^{\circ} \mathrm{C}$. $\mathrm{C}$ is the concentration of mercury not retained and $\mathrm{C}_{0}$ is the inlet concentration of mercury.

Two mechanisms of mercury adsorption could theoretically be expected, which can be summarized as: 1) $\mathrm{Hg}^{0}$ could be adsorbed directly in the active centers of the sorbent; 2) $\mathrm{Hg}^{0}$ could be oxidized on catalytic oxidation sites, if 
any, and then be adsorbed on the same active centers or migrate to adjacent noncatalytic adsorption sites. The results described below point to the first of these mechanisms.

Theoretical studies using density functional theory (DFT) have been reported to help understand the mechanisms at the molecular-level of the adsorption of mercury by iron oxides. Based on these DFT calculations, it has been found that the mechanism of capture of $\mathrm{Hg}^{0}$ by $\mathrm{y}-\mathrm{Fe}_{2} \mathrm{O}_{3}$ in coal-fired flue gases can take place by amalgamation being its capacity strongly dependent on the structure of $y-\mathrm{Fe}_{2} \mathrm{O}_{3}$ [19]. The presence of oxygen vacancies in $\mathrm{y}-\mathrm{Fe}_{2} \mathrm{O}_{3}$ leads to a strong interaction of mercury with the solid surface. The results of the present work indicate that the retention of $\mathrm{Hg}^{0}$ occurs directly and that the intermediate oxidation of $\mathrm{Hg}^{0}$ to $\mathrm{Hg}^{2+}$ does not take place. This is confirmed by the minimum concentration of $\mathrm{Hg}^{2+}(2 \%)$ detected during the adsorption and desorption experiments, which indicates that $\mathrm{y}-\mathrm{Fe}_{2} \mathrm{O}_{3}$ does not catalyze the formation of $\mathrm{Hg}^{2+}$, as previously observed in similar bench-scale experiments $[18,19]$. The results suggest that the mercury-sorbent interaction in an atmosphere of $\mathrm{N}_{2}+\mathrm{O}_{2}\left(13 \% \mathrm{v} / \mathrm{v} \mathrm{O}_{2}\right)$ occurs through a mechanism that involves the participation of iron oxide in the capture of $\mathrm{Hg}^{0}$ and where the capacity of the sorbent will be determined by the percentage of oxygen vacancies in ACFe10-800.

\subsubsection{Effect of flue gas composition}

The adsorption of mercury obtained for the ACFe10-800 sorbent in an atmosphere containing $27 \% \mathrm{v} / \mathrm{v} \mathrm{N}, 60 \% \mathrm{v} / \mathrm{v} \mathrm{CO}_{2}, 13 \% \mathrm{v} / \mathrm{v} \mathrm{O}, 100 \mathrm{ppm} \mathrm{SO} \mathrm{S}_{2}$ and 25 ppm $\mathrm{HCl}$ is shown in Fig.8. As can be observed, the sorbent ACFe10-800 
shows an efficiency of $100 \%$ for approximately $20 \mathrm{~h}$, at 40 and $140{ }^{\circ} \mathrm{C}$, which indicates that the active centers of the sorbent are not deactivated by the presence of these gases for at least two cycles of adsorption-desorption.
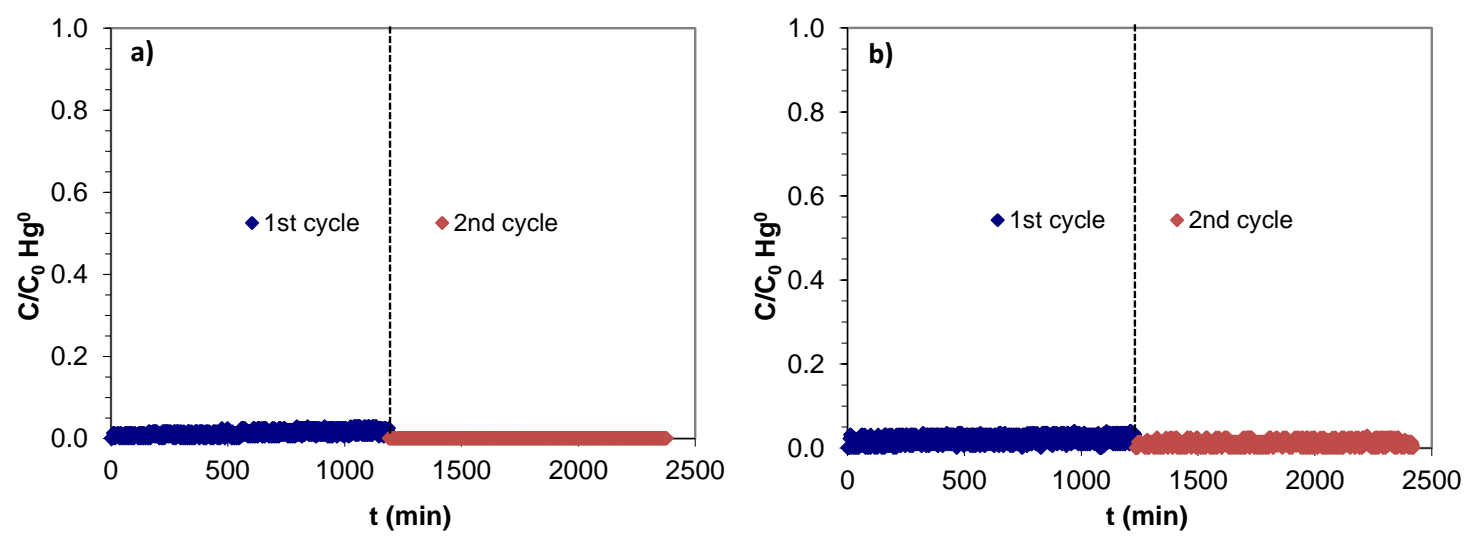

Fig. 8. Mercury adsorption for ACFe10-800 in an atmosphere of enriched $\mathrm{CO}_{2}$ $\left(27 \% \mathrm{v} / \mathrm{v} \mathrm{N}_{2}, 60 \% \mathrm{v} / \mathrm{v} \mathrm{CO}_{2}, 13 \% \mathrm{v} / \mathrm{v} \mathrm{O}_{2}, 100 \mathrm{ppm} \mathrm{SO} \mathrm{SO}_{2}\right.$ and $\left.25 \mathrm{ppm} \mathrm{HCl}\right)$ during two cycles of adsorption-desorption at: a) $140{ }^{\circ} \mathrm{C}$ and b) $40 \stackrel{\circ}{\circ}$.

Due to the low temperature required for regeneration $\left(450^{\circ} \mathrm{C}\right)$ compared to that used for the synthesis of the sorbent $\left(800^{\circ} \mathrm{C}\right)$, it is expected that there will be no changes in the structure of the sorbent as a consequence of the regeneration step. Although it could be expected that the presence of $\mathrm{O}_{2}$ or acid gases in the flue gas could modify the chemical surface of the material used as support or poison the sorbent, affecting its mercury adsorption capacity [28-31], the results show that the sorbent maintains its mercury removal capacity, approximately $320 \mathrm{\mu g} \mathrm{g}^{-1}$, at both reaction temperatures in the presence of these gases. 


\subsection{Future perspective}

This work is a basic research study aimed at understanding the behavior of new sorbents for the capture of gaseous $\mathrm{Hg}^{0}$. However, to take full advantage of their characteristics and performance in industrial applications, it will be necessary to define the basic and applied features in a future work. One is the evaluation of the lifetime of the sorbent, and the number of regeneration cycles that can be expected. The second, but also related to the previous one, is the definition and optimization of the operation conditions to carry out the scaling. This intermediate step would require the design of a prototype for the evaluation of the sorbent.

It should be noted that although the evaluation and development of sorbents doped with noble metals cannot be stopped, it would be of enormous interest to focus efforts on optimizing the type of sorbents developed and evaluated in this work. This is justified by reasons already explained throughout the work, which could be summarized in two: good performance and low price.

Although work has focused on the capture of gaseous $\mathrm{Hg}^{0}$ in energy production from coal and the sorbents have been tested in a $\mathrm{CO}_{2}$-enriched atmosphere, the developed activated carbon materials impregnated with maghemite are expected to be multipurpose sorbents for gas cleaning application in other industrial or environmental processes.

\section{Conclusions}

The results found in this study open up the possibility of using carbonaceous supports loaded with iron oxides as regenerable sorbents for the 
capture of mercury in energy generation processes. High mercury retention efficiency, regenerability and resistance to acid gases make activated carbons impregnated with maghemite an economical alternative to traditional regenerable sorbents. The high performance obtained at 40 and $140{ }^{\circ} \mathrm{C}$ would allow its use as regenerable fixed-beds at the end of the cycle or even by injection in the flue gas. The main mercury-sorbent interaction occurs in the oxygen defects of the maghemite structure that act as active centers for the adsorption of mercury.

Although the comparative evaluation of the regenerability of the sorbents developed with that of the sorbents doped with noble metals must be evaluated in detail, the results of this work suggest that sorbents impregnated with $\mathrm{Fe}$ in the form of maghemite achieve efficiencies similar to those obtained with noble metals.

\section{Acknowledgments}

The authors acknowledge the financial support, through the research projects CTQ2014-58110-R and GRUPIN14-031.

\section{References}

[1] UNEP. Global Mercury Assessment 2013: Sources, Emissions, Releases and Environmental Transport. Geneva, Switzerland: UNEP Chemicals Branch; 2013. 
[2] Wentz D, Brigham M, Chasar L, Lutz M, Krabbenhoft D. Mercury in the Nation's streams-Levels, trends, and implications. U.S. Geological Survey Circular 1395; 2014.

[3] Acuña-Caro C, Brechtel K, Scheffknecht G, Braß M. The effect of chlorine and oxygen concentrations on the removal of mercury at an FGD-batch reactor. Fuel. 2009;88(12):2489-94.

[4] Rodríguez-Pérez J, López-Antón MA, Díaz-Somoano M, García R, MartínezTarazona MR. Regenerable sorbents for mercury capture in simulated coal combustion flue gas. J Hazard Mater. 2013;260(Supplement C):869-77.

[5] Sjostrom S, Durham M, Bustard CJ, Martin C. Activated carbon injection for mercury control: Overview. Fuel. 2010;89(6):1320-2.

[6] Liu W, Vidić RD, Brown TD. Optimization of Sulfur Impregnation Protocol for Fixed-Bed Application of Activated Carbon-Based Sorbents for Gas-Phase Mercury Removal. Environmental Science \& Technology. 1998;32(4):531-8.

[7] Liu Y, Bisson TM, Yang H, Xu Z. Recent developments in novel sorbents for flue gas clean up. Fuel Process Technol. 2010;91(10):1175-97.

[8] Lopez-Anton MA, Fernández-Miranda N, Martínez-Tarazona MR. The application of regenerable sorbents for mercury capture in gas phase. Environ Sci Pollut Res. 2016;23(24):24495-503.

[9] Fernández-Miranda N, Rodríguez E, Lopez-Anton M, García R, MartínezTarazona M. A New Approach for Retaining Mercury in Energy Generation Processes: Regenerable Carbonaceous Sorbents. Energies. 2017;10(9):1311. [10] Hnydiuk-Stefan A, Składzień J. Analysis of supercritical coal fired oxy combustion power plant with cryogenic oxygen unit and turbo-compressor. Energy. 2017;128:271-83. 
[11] Nimmanterdwong P, Chalermsinsuwan B, Piumsomboon P. Emergy analysis of three alternative carbon dioxide capture processes. Energy. 2017;128:101-8.

[12] McGlade C, Speirs J, Sorrell S. Unconventional gas - A review of regional and global resource estimates. Energy. 2013;55:571-84.

[13] Liu Y, Kelly DJA, Yang H, Lin CCH, Kuznicki SM, Xu Z. Novel Regenerable Sorbent for Mercury Capture from Flue Gases of Coal-Fired Power Plant. Environmental Science \& Technology. 2008;42(16):6205-10.

[14] Ballestero D, Gómez-Giménez C, García-Díez E, Juan R, Rubio B, Izquierdo MT. Influence of temperature and regeneration cycles on $\mathrm{Hg}$ capture and efficiency by structured Au/C regenerable sorbents. J Hazard Mater. 2013;260(Supplement C):247-54 .

[15] Scala F, Cimino S. Elemental mercury capture and oxidation by a regenerable manganese-based sorbent: The effect of gas composition. Chem Eng J. 2015;278(Supplement C):134-9.

[16] Dunham GE, DeWall RA, Senior CL. Fixed-bed studies of the interactions between mercury and coal combustion fly ash. Fuel Process Technol. 2003;82(2-3):197-213.

[17] Yang Y, Liu J, Wang Z, Liu F. Heterogeneous reaction kinetics of mercury oxidation by $\mathrm{HCl}$ over $\mathrm{Fe} 2 \mathrm{O} 3$ surface. Fuel Process Technol. 2017;159(Supplement C):266-71.

[18] Galbreath KC, Zygarlicke CJ, Tibbetts JE, Schulz RL, Dunham GE. Effects of $\mathrm{NOx}, \mathrm{\alpha}-\mathrm{Fe} 2 \mathrm{O} 3, \mathrm{y}-\mathrm{Fe} 2 \mathrm{O} 3$, and $\mathrm{HCl}$ on mercury transformations in a $7-\mathrm{kW}$ coal combustion system. Fuel Process Technol. 2005;86(4):429-48. 
[19] Guo P, Guo X, Zheng C. Roles of $\mathrm{Y}-\mathrm{Fe} 2 \mathrm{O} 3$ in fly ash for mercury removal: Results of density functional theory study. Appl Surf Sci. 2010;256(23):6991-6. [20] Yang J, Zhao Y, Ma S, Zhu B, Zhang J, Zheng C. Mercury Removal by Magnetic Biochar Derived from Simultaneous Activation and Magnetization of Sawdust. Environmental Science \& Technology. 2016;50(21):12040-7.

[21] Dobrowolski R, Otto M. Preparation and evaluation of Fe-loaded activated carbon for enrichment of selenium for analytical and environmental purposes. Chemosphere. 2013;90(2):683-90.

[22] Fernández-Miranda N, Rumayor M, Lopez-Anton MA, Díaz-Somoano M, Martínez-Tarazona MR. Mercury Retention by Fly Ashes from Oxy-fuel Processes. Energy \& Fuels. 2015;29(4):2227-33.

[23] Fuente-Cuesta A, Diaz-Somoano M, Lopez-Anton MA, Martinez-Tarazona MR. Oxidised mercury determination from combustion gases using an ionic exchanger. Fuel. 2014;122(Supplement C):218-22.

[24] Herranz T, Rojas S, Ojeda M, Pérez-Alonso FJ, Terreros P, Pirota K, et al. Synthesis, Structural Features, and Reactivity of Fe-Mn Mixed Oxides Prepared by Microemulsion. Chem Mater. 2006;18(9):2364-75.

[25] Rochelle M. Cornell US. The Iron Oxides: Structure, Properties, Reactions, Occurrences and Uses, Completely Revised and Extended Edition (2nd). Weinheim: Wiley-VCH 2004. p. 9-38.

[26] Santoyo Salazar J, Perez L, de Abril O, Truong Phuoc L, Ihiawakrim D, Vazquez M, et al. Magnetic Iron Oxide Nanoparticles in 10-40 nm Range: Composition in Terms of Magnetite/Maghemite Ratio and Effect on the Magnetic Properties. Chem Mater. 2011;23(6):1379-86. 
[27] Kim W, Suh C-Y, Cho S-W, Roh K-M, Kwon H, Song K, et al. A new method for the identification and quantification of magnetite-maghemite mixture using conventional X-ray diffraction technique. Talanta. 2012;94(Supplement C):348-52.

[28] Kwon S, Borguet E, Vidic RD. Impact of Surface Heterogeneity on Mercury Uptake by Carbonaceous Sorbents under UHV and Atmospheric Pressure. Environmental Science \& Technology. 2002;36(19):4162-9.

[29] Liu T, Xue L, Guo X, Zheng C-G. DFT study of mercury adsorption on $\alpha$ Fe2O3 surface: Role of oxygen. Fuel. 2014;115:179-85.

[30] Hall B, Schager P, Weesmaa J. The homogeneous gas phase reaction of mercury with oxygen, and the corresponding heterogeneous reactions in the presence of activated carbon and fly ash. Chemosphere. 1995;30(4):611-27.

[31] Presto AA, Granite EJ. Impact of Sulfur Oxides on Mercury Capture by Activated Carbon. Environmental Science \& Technology. 2007;41(18):6579-84. 